\title{
DESIGN OF TUNED REED COURSE INDICATORS FOR AIRCRAFT RADIOBEACON
}

\author{
By F. W. Dunmore
}

\begin{abstract}
The tuned reed indicator is a simple and reliable instrument for use in connection with the radiobeacon system developed by the Bureau of Standards for guiding aircraft. This beacon system was developed with a view to giving a pilot a visual indication as to whether or not he is flying on a specified course, and if not, to which side and how much he has deviated. This indication is given by two vibrating reeds, the relative amplitudes of vibration of which indicate the position of the airplane with respect to the beacon course. Equal amplitude of the two reeds indicates that the airplane is on the course. The reeds give a continuous indication to the pilot of his position with respect to his course. This indication is obtained without any other effort than a glance of the eye. This feature is particularly valuable, since in time of fog, when the device is most needed, the pilot is very much occupied and can only glance at a course-indicating device occasionally.

The reed indicator consists of a pair of metal reeds capable of vibrating between a pair of small electromagnets. These electromagnets are connected to the output terminals of the airplane receiving set. The free end of each reed carries a white vane. This produces two white lines close together when the reeds vibrate. These two lines are what the pilot observes when holding a beacon course. Owing to the mechanical tuning of the reeds they are extremely free from the effects of all kinds of interference unless the interference is strong enough to block the tubes in the receiving set.

Six types of indicators were constructed and data obtained on each. The final model was one in which the reeds were made of steel with a bimetallic strip on the free end of the reeds for automatically holding the reeds in tune as the temperature varies. The reeds which are strongly polarized vibrate between two electromagnets taken from a telephone receiver. This form of indicator requires less than 1.5 milliamperes and 3.5 volts to operate the reeds, with a 11 by $11 \mathrm{~mm}$ damper on the end of the reed. This damper served to incmease the decrement of the reed, so that any slight changes in the modulation frequencies would not change the reed deflections.

This indicator unit is arranged to plug into a shock-proof mounting on the instrument board of the airplane. With mounting its dimensions are $31 / 2$ by $23 / 4$ by $4 \frac{1}{2}$ inches, and weighs under 2 pounds,
\end{abstract}

$$
8431^{\circ}-28-1
$$


I. Introduction

II. Choice of modulation frequencies

III. Description of several types of indicators

1 Experimental type, with marker beacon reed, type A.....

2. Multireed indicator, type B.

758

3. Single-coil reed indicator, type $\mathrm{C}_{\ldots}$

4. Plug-in type of indicator, type D

761

5. Rear-drive, nonpolarized indicator, type $\mathbf{E}_{\ldots}$

6. Rear-drive, polarized reed, type $\mathrm{F}_{\ldots}$

\section{INTRODUCTION}

The tuned reed type of visual indicator is a simple and reliable instrument for use on airplanes in connection with the double modulation type radiobeacon. ${ }^{1}$ This beacon system was developed with a view to giving a pilot a visual indication as to whether or not he is flying on a specified course, and if not, to which side and how much he has deviated. This indication is given by two vibrating reeds, the relative amplitudes of vibration of which indicate the position of the airplane with respect to the beacon course. The reeds give a continuous reading indication to the pilot, free from the effects of ignition and other interferences, yet they are sufficiently sensitive to operate from the output of an aircraft receiving set and small enough to be placed on the instrument board of an airplane.

The radiobeacon, in connection with which the reed indicator operates, is a transmitting station which sends out 290-kilocycle waves on two loop antennæ. These antennæ are at right angles to each other, and the waves from one are modulated at a certain low frequency, such as 65 cycles, and the other at another low frequency, as 85 cycles. A figure-of-eight characteristic is produced in space, and there are two lines (or four directions) along which the two modulated signals are of equal intensity. These directions are the courses where the two reeds of the visual indicator vibrate with equal amplitudes.

The reed indieator consists of a pair of metal reeds capable of vibrating between a pair of small electromagnets. These electromagnets are connected to the output terminals of the airplane receiving set. The frequencies to which the two vibrating reeds are tuned are the modulation frequencies supplied to the two transmitting antennæ at the beacon station. This paper describes the development of the reed indicators, with special reference to choice of the modulation frequencies.

\footnotetext{
1 "Development of radio aids to air navigation." J. H. Dellinger and H. Pratt, Proc. I. R. E., 16, p.
} 890-920; July, 1928. 
B. S. Journal of Research, RP28

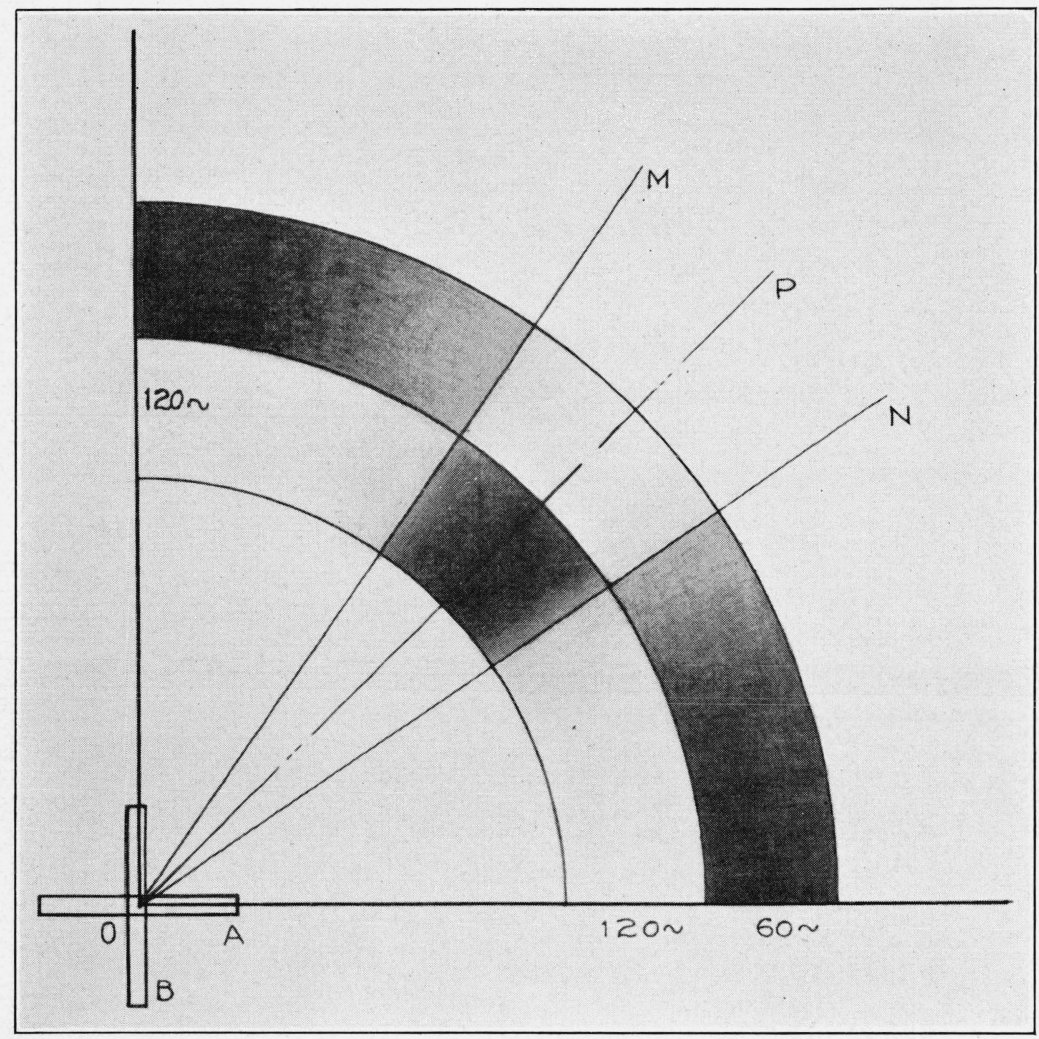

FIG. 1.-Transmission characteristic of beacon modulated at 60 cycles, pushpull fashion. Degree of shading shows amount of modulation present 


\section{CHOICE OF MODULATION FREQUENCIES}

The choice of modulation frequencies which may be used in the beacon station is essentially determined by the characteristics of the indicators used on the airplane. In order to obtain an appreciable amplitude of reed vibration in the indicators, it is necessary to use a reed of sufficient length to give at least $1 \mathrm{~cm}$ deflection. Low frequencies were, therefore, chosen, of the order of 50 to 100 cycles. Aside from making possible the use of a sufficiently long reed in the indicator, the use of these frequencies had the added advantage that, owing to the narrow side bands when modulating the carrier at two of these frequencies, a change in tuning of the receiving set operating the reeds will not cause an apparent shift in the course due to the relative change in the side band amplitudes. A detuning of the receiving set by 100 cycles throws out both frequencies, while if 500 or 1,000 cycles were used and the set detuned by 500 cycles most of the 500 cycles would be tuned out while much of the side band from the 1,000 cycles would remain.

In the first experiments to determine suitable modulation frequencies 60 cycles was chosen as one frequency, since it could easily be obtained from the power lines. The circuit consists of a master oscillator, the radio-frequency output of which is amplified by two amplifier tubes $I_{1}$ and $I_{2}$. The plate of $I_{1}$ is supplied with high voltage at 85 cycles through transformer $F$ and passes radio-frequency on to one coil antenna modulated at this frequency through coils $C$ and $L$, while the other tube passes the same radio-frequency modulated at 65 cycles by transformer $G$ to the other coil antenna through coils $M$ and $P$. In these first tests one center-tapped 60 -cycle transformer was used in place of transformers $F$ and $G$. The effect of this combination was to operate the power amplifier tubes $I_{1}$ and $I_{2}$ in pushpull fashion, so that radio-frequency power is passed through coils $C-L$ and $M-D$ every other half cycle.

An advantage of the push-pull arrangement is that there can be no coupling between power amplifier circuits or between goniometer stators, since the push-pull circuit causes one power amplifier to be completely inactive while the other is functioning, due to the negative potential on one plate while the plate of the other tube is positive. The effect produced in space is that shown in Figure 1, in which the relative amounts of shading in the outer segment represent the amount of 60-cycle signal present and a similar effect in the inner segment represents the amount of 120 -cycle signal present. Since the signals received along the line $O P$ from loops $A$ and $B$ are of equal amplitude and come alternately, two every 60 cycles, the audiofrequency signal in this region will be 120 cycles. In this system, therefore, the second reed was tuned to 120 cycles. With this 
method there are two courses for each quadrant, one being along the line $O N$, where the 60 and 120 cycle modulation are present with equal amounts and the other along the line $O M$ where the two frequencies are likewise present in equal amounts.

It was found during experiments with this system that the two courses could readily be found. In fact, there were really eight courses, two for each quadrant. These were found by rotating the courses through $360^{\circ}$ while receiving the 120 and 60 cycle signal at a

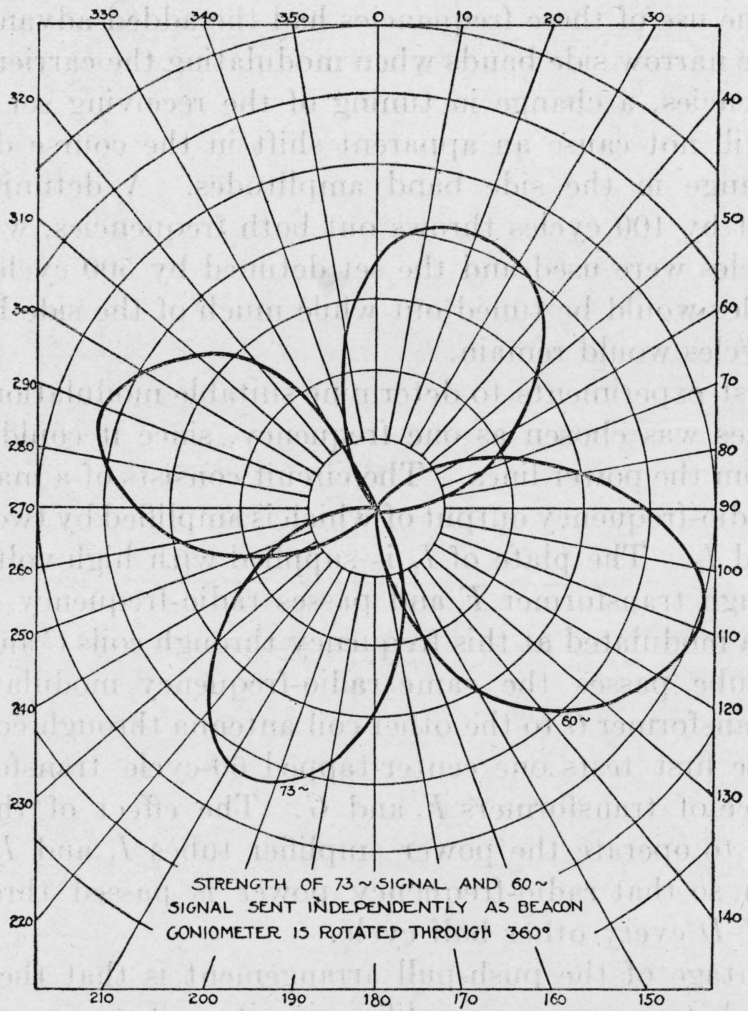

FIG. 2.-Resultant field with beacon antennas modulated, one at 60 cycles and the other at 73 cycles

fixed location and watching the reed indicator. In this way all eight courses could be swept through the receiving point. Although the transmitting circuit for this system is simple, several disadvantages were found from the point of view of the reeds. The principal objection was that the 120-cycle reed being tuned to a harmonic of 60 cycles was caused to operate by the 60 -cycle frequency. Although the amplitude of the vibration due to this effect was small, it was sufficient to broaden the course. Another disadvantage was that the 120-cycle reed, being considerably shorter than the 60-cycle reed, 
gave a much less amplitude of vibration than the 60-cycle reed for an equal audio-frequency input. The sharpness of the course is greater when turning into the 120-cycle zone than when turning in the opposite direction toward the 60-cycle zone. The two courses, $O M$ and $O N$ (fig. 1), might cause some confusion, since they are within 15 or $20^{\circ}$ of each other, and the pilot might accidentally shift from one course to the other without knowing it. For these reasons this method of modulation at the beacon was discarded for the one in

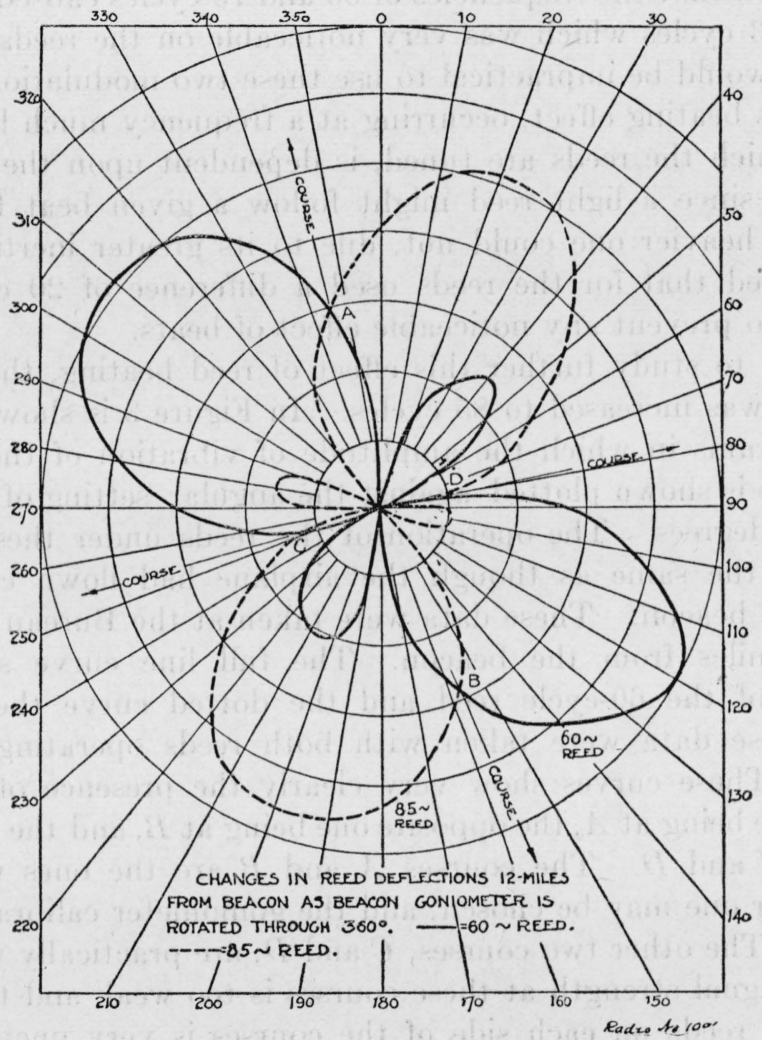

FIg. 3.-Polar curves obtained by measuring the amplitudes of vibration of the 60 and 85 cycle reeds as beacon course is changed through $360^{\circ}$

which two sources of audio-frequency modulations were used independently of each other.

The next problem was to determine the two best modulating frequencies. Sixty cycles was again chosen as one frequency, since it could be so easily obtained from the power line and since the length of the reed which tuned to this frequency was sufficient to give ample movement at the free end without being too long to be affected by mechanical vibrations. The other frequency, as first chosen, was 
73 cycles. Figure 2 shows polar curves taken using these two frequencies with thermoelements in the output of a radio receiving set. These curves were taken as the goniometer was rotated through $360^{\circ}$, thus swinging the courses past the receiving point. The curve for 60 cycles was taken with the 73-cycle power off and the curve for 73 cycles with the 60 -cycle power off. When both frequencies of modulation were applied simultaneously and a reed indicator with reeds tuned to 60 and 73 cycles was put in place of the thermoelement, it was found that the frequencies of 60 and 73 cycles caused a beating effect at 13 cycles which was very noticeable on the reeds; so much so that it would be impractical to use these two modulation frequencies. This beating effect, occurring at a frequency much lower than that to which the reeds are tuned, is dependent upon the inertia of the reeds, since a light reed might follow a given beat frequency, whereas a heavier one could not, due to its greater inertia. Later tests showed that for the reeds used a difference of 20 cycles was sufficient to prevent any noticeable effect of beats.

In order to study further this effect of reed beating, the 73-cycle frequency was increased to 85 cycles. In Figure 3 is shown a set of polar diagrams in which the amplitude of vibration of the reeds in millimeters is shown plotted against the angular setting of the goniometer in degrees. The operation of the reeds under these circumstances is the same as though the airplane had flown completely around the beacon. These data were taken at the Bureau of Standards, 12 miles from the beacon. The full line curve shows the operation of the 60-cycle reed and the dotted curve the 85-cycle reed. These data were taken with both reeds operating simultaneously. These curves show very clearly the presence of the four courses, one being at $A$, the opposite one being at $B$, and the other two being at $C$ and $D$. The courses $A$ and $B$ are the ones which are used; either one may be chosen, and the goniometer calibrated using this one. The other two courses, $C$ and $D$, are practically worthless, since the signal strength at these courses is too weak and the operation of the reeds on each side of the courses is very uneven. The smaller polar curves within the larger ones are due to coupling between the two power amplifiers and goniometer stator coils. With the courses $A$ and $B$ the amplitude of vibration of one reed drops evenly, while that of the other reed rises in a similar fashion as the pilot deviates from the course. Although the two beacon loops, $A$ and $B$, are at right angles as well as the goniometer stators and rotors, it will be noted that the minimum of 60 -cycle signal and minimum of 85-cycle signal do not occur at points separated by $90^{\circ}$. Instead, this angle is about $60^{\circ}$. From Figure 3 it will be noted that if a pilot deviates from his course at $A$ by $25^{\circ}$ to the right, the 60-cycle reed 
will decrease in amplitude until it becomes stationary, while the 85cycle reed would vibrate with nearly maximum amplitude at this point. If he deviates by $35^{\circ}$ in the opposite direction to the left, the 85-cycle reed will drop to a stationary position and the 60-cycle reed will be vibrating with maximum amplitude. The effect is shown in more graphical form in Figure 4, which is self-explanatory. From

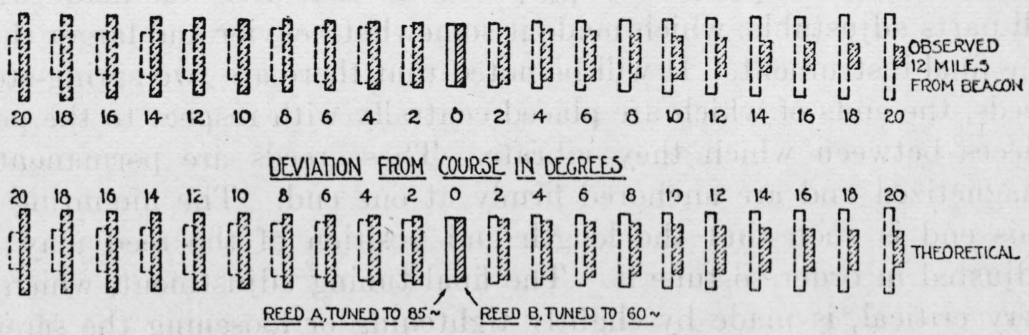

FIG. 4.-Relative change in amplitude of reed vibrations as airplane deviates from the course

the operation of the reeds as shown in Figure 4, it is evident that the relative amplitudes of the two reeds enables the pilot to judge to a large extent as to the number of degrees he has deviated from the course either to the right or left and still indicate to him which side he is off. This feature of the reed indicator is very useful, since it is frequently necessary to make large detours to avoid storms or other hazards to flying, in which case the pilot knows at all times to what degree he has deviated from the course and how to turn to return to it.

The particular field strength patterns using the two frequencies of modulation, as shown in Figure 3, were produced by the certain combination of conditions at the beacon transmitter. Instead of being two figure-of-eight's oriented at $90^{\circ}$, they produce a much better field strength pattern with a strong signal in the direction of the two courses and a much weaker one at $90^{\circ}$, thus cutting down interference produced by the beacon; also, the slope of the curves at the intersection is greater than if they had been circles, thus giving a sharper course indication.

Since very good operation of both the beacon and reed indicator was obtained when using 60 and 85 cycles as the modulation frequencies, these two were adopted and the reeds designed accordingly.

\section{DESCRIPTION OF SEVERAL TYPES OF INDICATORS}

In order to obtain a satisfactory reed indicator suitable for use on aircraft, several models were successively designed and experimented with. These various models are designated below as types A, B, C, $\mathrm{D}, \mathrm{E}$, and F. The type $\mathrm{F}$ indicator is the most satisfactory of these. 
1. EXPERIMEITAL TYPE, WITH MARKER BEACON REED, TYPE A

Several forms of this type of indicator were constructed and tried out. In this type the reeds are permanently magnetized, the driving electromagnets operating on the free end of the reeds. The first one was made using the electromagnets from an ordinary telephone receiver. One of the indicators constructed in this way is shown in Figure 5. For experimental purposes this indicator was made with all parts adjustable, which made it somewhat heavier and larger than the final instrument. It will be noted that there are two spring-steel reeds, the ends of which are placed centrally with respect to the pole pieces between which they vibrate. These reeds are permanently magnetized and are anchored firmly at one end. The mounting at this end is such that the length and position of the reed may be adjusted in order to tune it. The final tuning adjustment, which is very critical, is made by slightly tightening or loosening the screws through the clamps which hold the reeds in place. The tip of the reed is provided with a small light vane painted white, so that when the reed vibrates a clear white line is produced. The 60 -cycle reed is approximately $60 \mathrm{~mm}$ long, $3.2 \mathrm{~mm}$ wide, and $0.28 \mathrm{~mm}$ thick. The 85-cycle reed is about $50 \mathrm{~mm}$ long, $2.7 \mathrm{~mm}$ wide, and $0.28 \mathrm{~mm}$ thick. Reeds of this width were necessary in this model, as they are acted upon at their free end by the electromagnets. Since it was necessary that these reeds be operated from the output of the radio receiving set on the plane, it was necessary that they be sufficiently sensitive to give full amplitude of vibration with normal output of the receiving set. This was accomplished by using two electromagnets acting push-pull fashion on a magnetized polarizing reed and by matching the impedance of the reed coils to that of the last tube on the receiving set. When this type of indicator was tried out without extra damping, it was found that it required somewhat less than 2 milliamperes to give full amplitude of vibration. Data taken at 60 cycles on this indicator showed that it had an impedance of 3,180 ohms, the direct-current resistance was $2,200 \mathrm{ohms}$, and 1.78 milliamperes at 60 cycles caused the 60 -cycle reed to deflect $1 \mathrm{~cm}$. The single reed on the right in Figure 5 is the marker beacon reed, to be described in a forthcoming paper. The two extra electromagnet coils for operating this reed were not included in the circuit when the above measurements of resistance and impedance were made.

The white vane on the ends of the reeds was made as light as possible. This was done for two reasons: (1) The greater the weight on the tip of the reed the more susceptible it is to the effect of mechanical vibrations; (2) the lighter the vane on the end of the reed the less the mechanical selectivity, since a weight on the end of a tuned reed acts like inductance in a tuned circuit, the resonance curve is sharper. It is important that the reeds be not too selective, since any slight 




FIG. 5.-Type A indicator, with forward drive and magnetized reeds

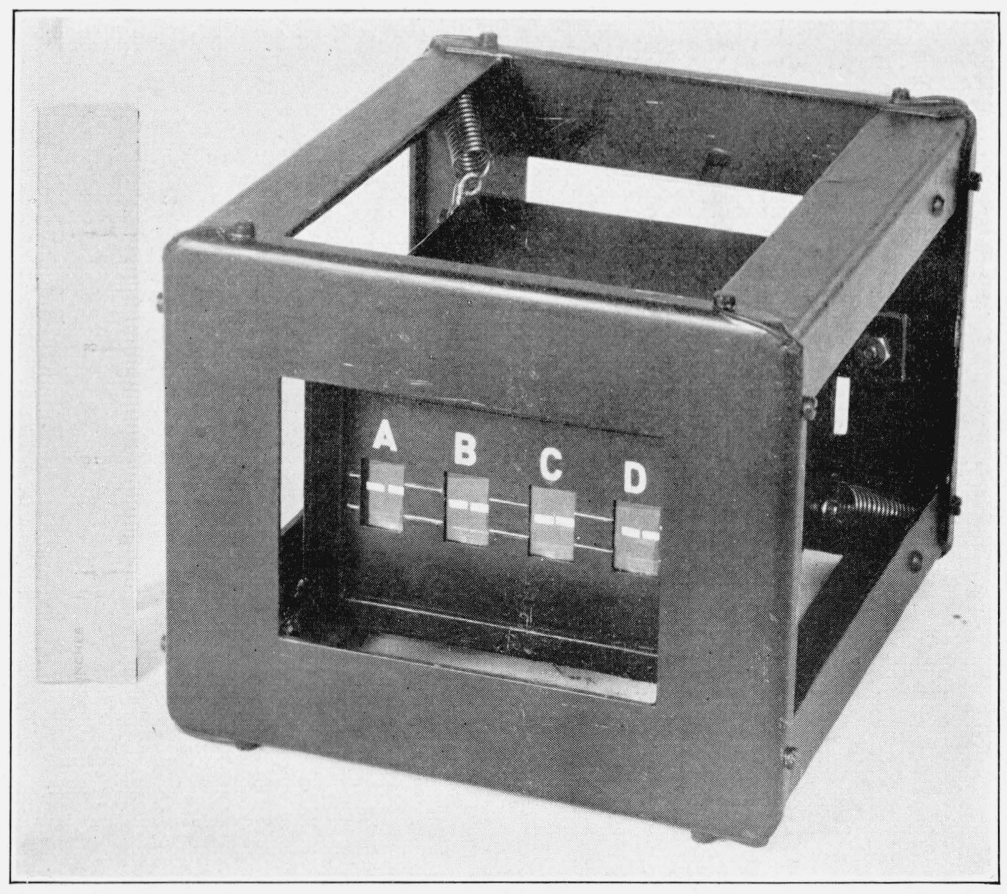

FIG. 7.-Type B indicator, multi-reed type, with shock-proof mounting 
change in the modulation frequency at the beacon would result in a decreased amplitude of reed vibration, thus causing an apparent shift in course.

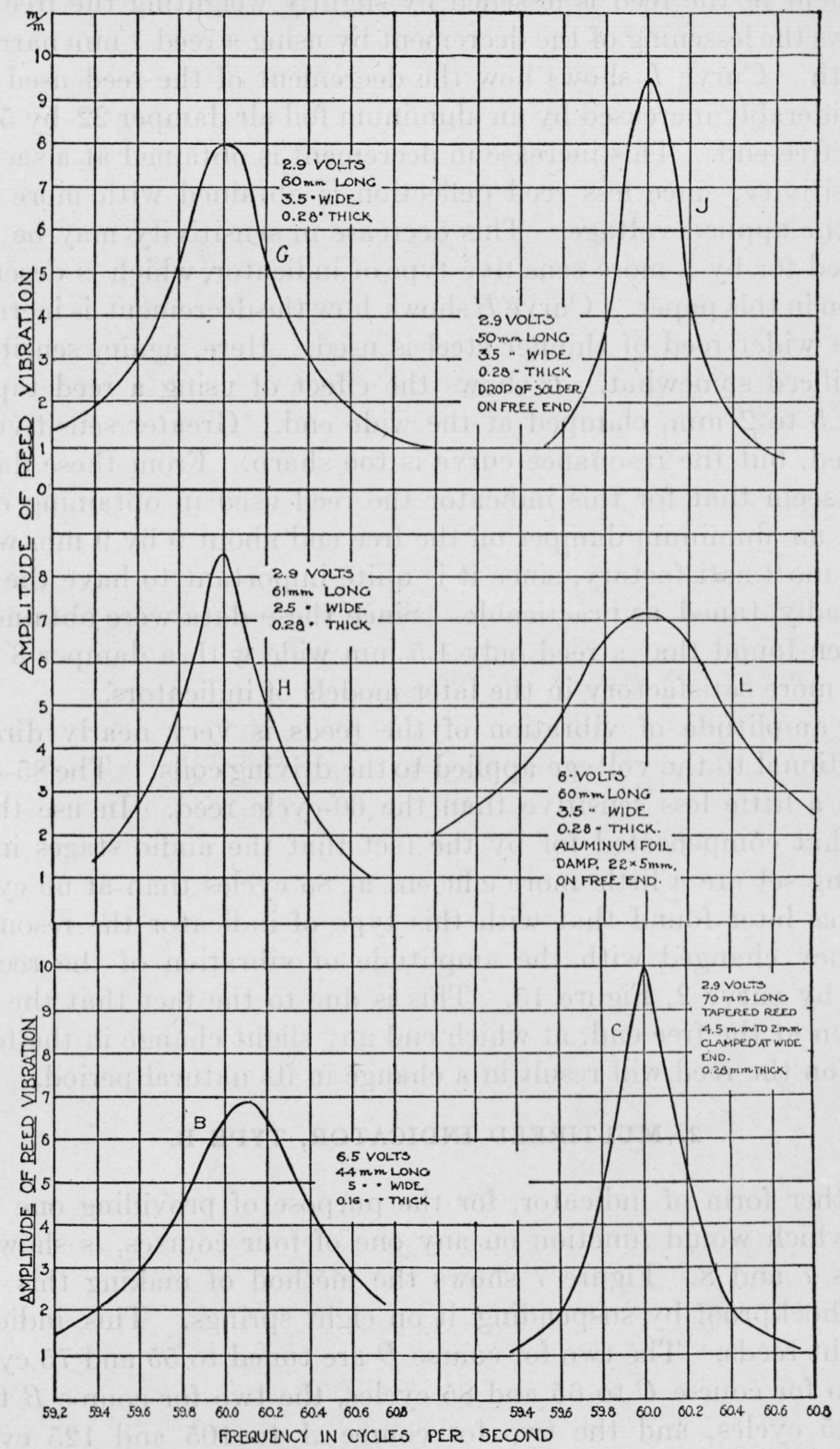

FIG. 6.-Resonance curves for various reeds

Because of this a study was made of different types of reeds in order to obtain one with as high a decrement as possible, yet sufficiently sensitive. The resonance curves shown in Figure 6 show 
how the reed characteristics in the type A indicator may be varied. Curve $G$ shows the resonance curve for a convenient size of spring steel reed without weight on the free end. Curve $J$ shows how the decrement of the reed is lessened by slightly weighting the free end. $H$ shows the lessening of the decrement by using a reed $1 \mathrm{~mm}$ narrower in width. Curve $L$ shows how the decrement of the reed used in $G$ is considerably increased by an aluminum foil air damper 22 by $5 \mathrm{~mm}$, on the free end. This increase in decrement is obtained at a sacrifice of sensitivity, since less reed deflection is obtained with more than twice the applied voltage. This decrease in sensitivity may be compensated for by a more sensitive type of indicator, which is described later on in this paper. Curve $B$ shows how the decrement is increased when a wider reed of thinner steel is used. Here, again, sensitivity is sacrificed somewhat. $C$ shows the effect of using a reed tapered from 4.5 to $2 \mathrm{~mm}$, clamped at the wide end. Greater sensitivity is obtained, but the resonance curve is too sharp. From these data it would seem that for this indicator the reed used in obtaining curve $G$ with an aluminum damper on the free end about 9 by $9 \mathrm{~mm}$ would be the most satisfactory, since it is quite important to have the reed as broadly tuned as practicable. Since these data were obtained it has been found that a reed only $1.5 \mathrm{~mm}$ wide with a damper 8 by 8 $\mathrm{mm}$ is more satisfactory in the later models of indicators.

The amplitude of vibration of the reeds is very nearly directly proportional to the voltage applied to the driving coils. The 85-cycle reed is a little less sensitive than the 60 -cycle reed. In use this is somewhat compensated for by the fact that the audio stages in the receiving set are a little more efficient at 85 cycles than at 60 cycles.

It was later found that with this type of indicator the resonance frequency changed with the amplitude of vibration of the reed as shown by curve 2, Figure 15 . This is due to the fact that the reed is driven at the free end, at which end any slight change in the forces acting on the reed will result in a change in its natural period.

\section{MULTIREED INDICATOR, TYPE B.}

Another form of indicator, for the purpose of providing one indicator which would function on any one of four courses, is shown in Figures 7 and 8 . Figure 7 shows the method of making this indicator shockproof by suspending it on eight springs. This indicator has eight reeds. The two for course $D$ are tuned to 55 and 75 cycles, the two for course $C$ to 65 and 85 cycles, the two for course $B$ to 95 and 115 cycles, and the two for course $A$ to 105 and 125 cycles. This combination made an indicator which might be used on any one of four courses, $A, B, C$, or $D$, which may be sent out from a given beacon, provided they are sent on slightly different carrier 


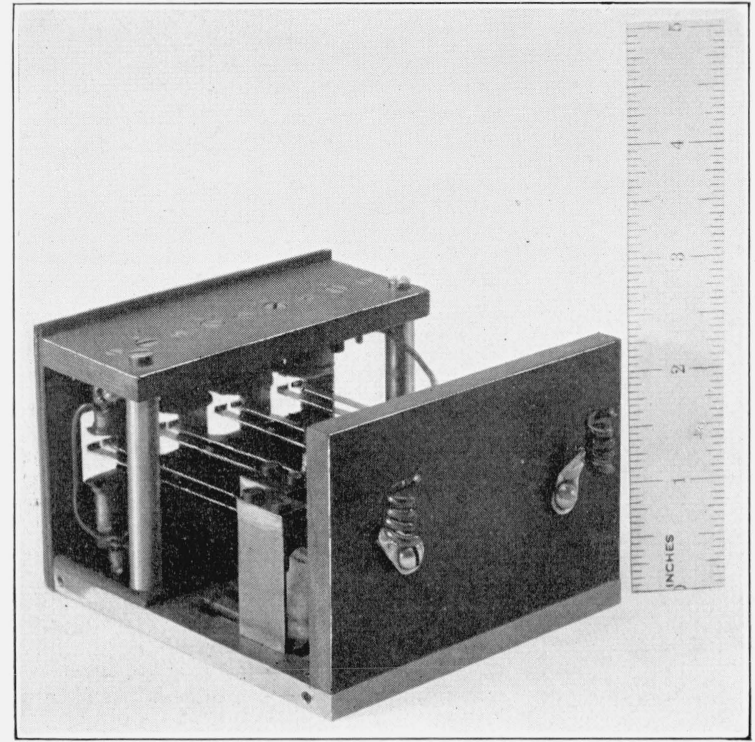

FIG. 8.-Interior of type $B$ indicator

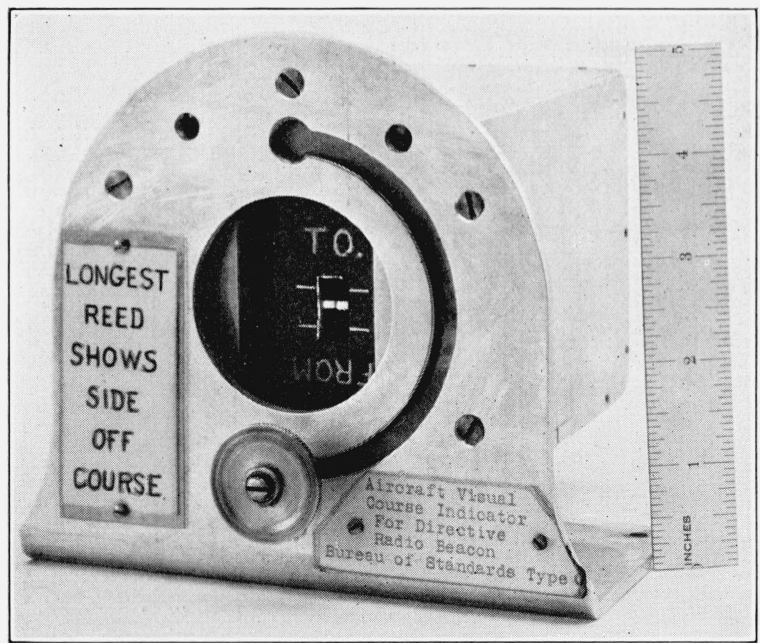

FIG. 9.-Type $C$ indicator, with pivoted mounting for turning it upside down 


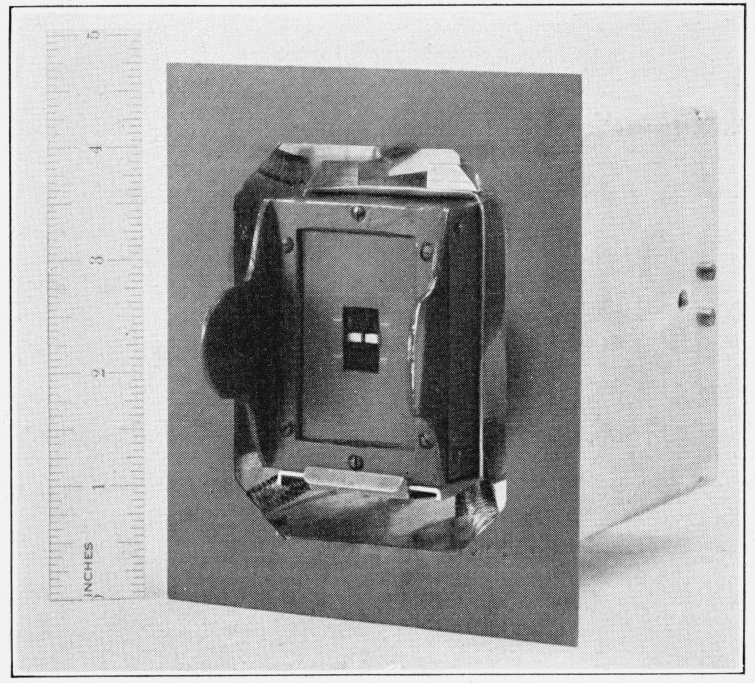

FIG. 11.-Type D indicator, with shock-proof mounting

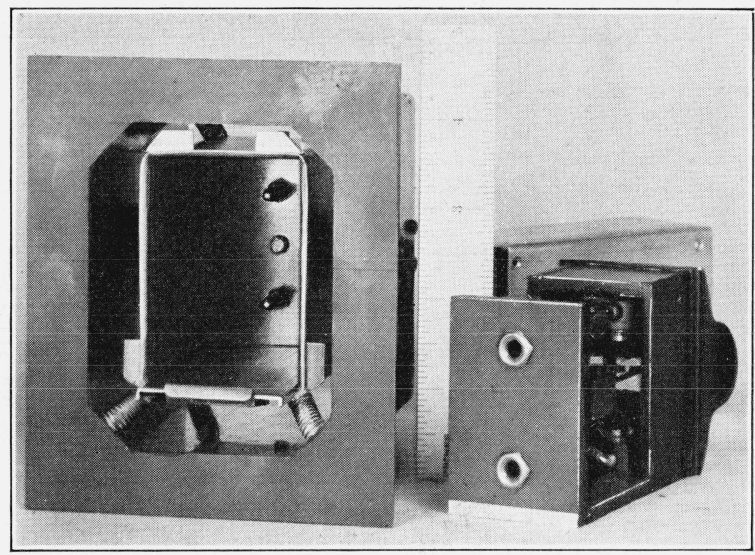

FIG. 12.-Type D inticator, showing plug-in connection

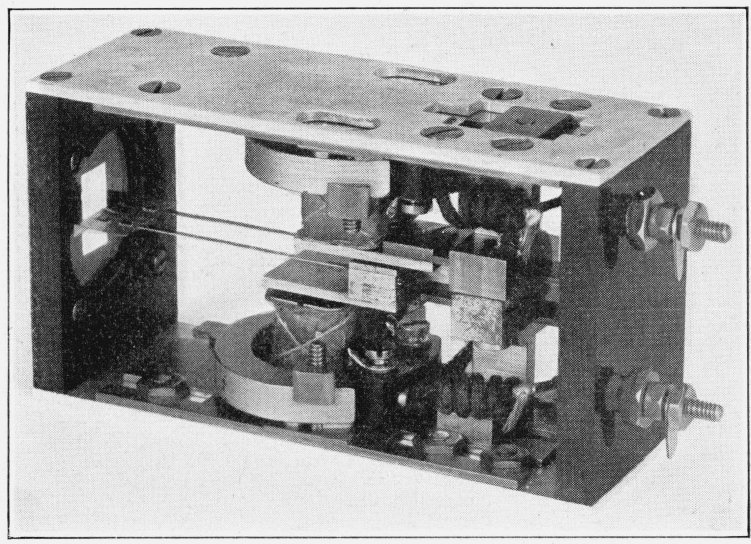

Fig. 13.-Type E indicator, nonpolarized rear drive 
frequencies. Thus, if the pilot is flying on course $B$, he would observe the second set of reeds only, which would be operated only by the beacon signal when it is oriented on course $B$. When the signal is oriented on courses $A, C$, and $D$, the modulation frequency and carrier frequency being changed, $B$ reeds are stationary. This type of indicator was found to be rather insensitive due to the necessity of using many electromagnets in series for driving the eight reeds. This might be overcome by a switching device for connecting in circuit any one set of two driving coils.

\section{SINGLE-COIL REED INDICATOR, TYPE C}

This type of indicator differs considerably in design from the ones described and was made in the attempt to obtain an indicator of greater sensitivity. It is shown in Figure 9. Figure 10 shows the
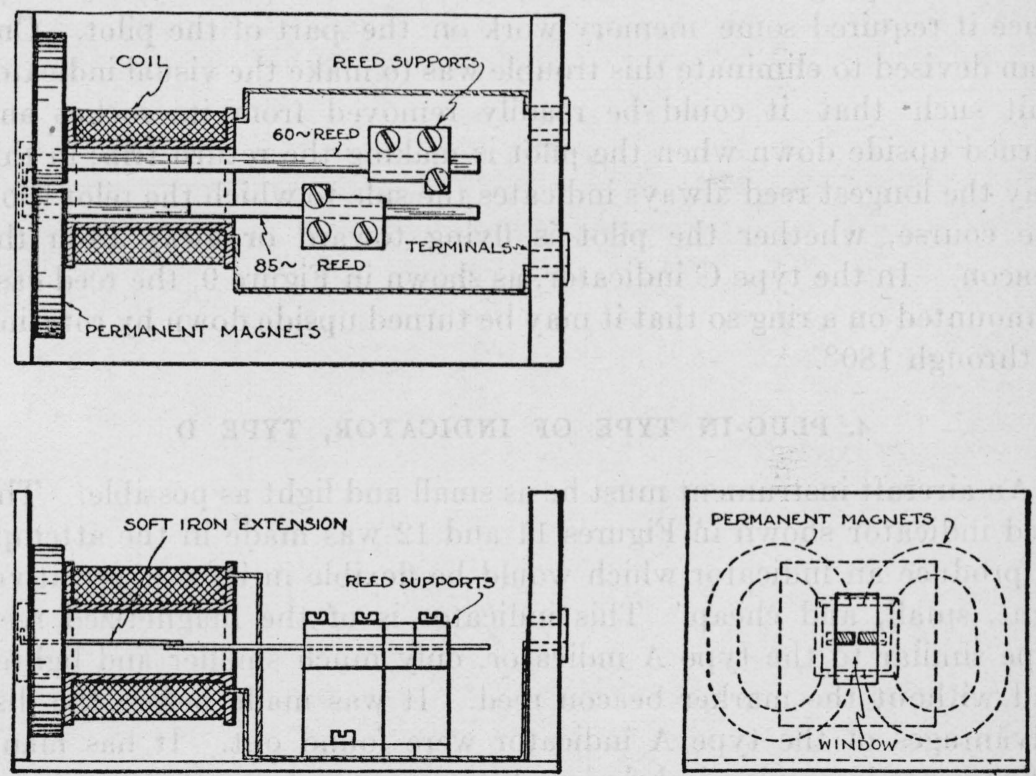

FIG. 10.-Principle of design of type $C$ indicator

details of construction. The reeds are not magnetized in this indicator, but both vibrate in the center of the coil of about 12,000 turns of No. 28 enameled wire. The reeds are of spring steel, but the ends within the coil have attached to them a little strip of corrugated soft iron about 1 inch long cut from a telephone receiver diaphragm. The magnets from the telephone receivers are placed at the free ends of the reeds. The polarity of the soft iron tips follows that of the alternating flux within the coil which carries the 60 and 85 cycle frequency. As these soft-iron tips are within the field of permanent 
magnets, they are attracted and repelled with the changing flux, causing the reeds to vibrate. This type of indicator gave a deflection of the 60-cycle reed of $13 \mathrm{~mm}$ for 1.45 mils of 60 -cycle current in the coil. This deflection was without damping. It has an impedance at this frequency of $5,030 \mathrm{ohms}$ and a direct current resistance of 3,100 ohms. This indicator was made shock proof by mounting it in a box lined with light sponge rubber. It was found that the resonance frequency of this indicator changed considerably with amplitude, as shown by curve 3, Figure 15 .

During the early trials of these indicators in actual flight tests a rather troublesome feature was found regarding the use of the reed type of visual indicator, since the pilot was required to turn in the direction of the shortest reed to get back on the course when flying away from the beacon, whereas he was required to turn to the longest reed when flying toward the beacon. This effect was very confusing, since it required some memory work on the part of the pilot. One plan devised to eliminate this trouble was to make the visual indicator unit such that it could be readily removed from its socket, and turned upside down when the pilot is making the return trip; in this way the longest reed always indicates the side to which the pilot is off the course, whether the pilot is flying toward or away from the beacon. In the type $\mathrm{C}$ indicator, as shown in Figure 9, the reed case is mounted on a ring so that it may be turned upside down by rotating it through $180^{\circ}$.

\section{PLUG-IN TYPE OF INDICATOR, TYPE D}

An aircraft instrument must be as small and light as possible. The reed indicator shown in Figures 11 and 12 was made in the attempt to produce an indicator which would be flexible in its use, sensitive, light, small, and cheap. This indicator is of the magnetized reed type similar to the type A indicator, only much smaller and lighter and without the marker beacon reed. It was made before the disadvantages of the type A indicator were found out. It has many refinements in mechanical design, however, which were incorporated in the later models. Four driving coils similar to those used in the type $\mathrm{A}$ indicator are used in this indicator. Figure 11 shows the indicator in position in its shock-proof case, and Figure 12 shows the case and indicator removed. The indicator has two plug terminals and the case two sockets permanently connected to the receiving set. Iu this way the indicator is automatically connected to the receiving set when it is plugged into its shock-proof case. The case is designed for panel mounting. Figure 21 shows the indicator mounted on the instrument board of an airplane. The words "From Beacon" appear right side up, and the words "To Beacon" upside down, showing that it is plugged in for a flight from the beacon. The indicator weighs 
$1 / 2$ pound without the shock-proof mounting, and is $15 / 3$ by $23 / 8$ by $3 \frac{7}{16}$ inches. With the mounting it weighs $11 / 4$ pounds and is $31 / 2$ by $23 / 4$ by $41 / 2$ inches. As it has but two reeds, it may be used only on one air route, but since it is of the plug-in type it may readily be removed from its shock-proof mounting and a similar indicator plugged in with reeds tuned to the course frequencies of whichever route the plane is to fly over. This type of plug-in indicator has several advantages over the multireed type of indicator. It may be made much smaller and lighter. It is more sensitive, since there are but two reeds to be operated. It may be easily removed from circuit for inspection. It may be quickly plugged in upside down when making the return trip. Any number of different courses may be flown by plugging in an indicator tuned to the desired course frequencies, since it is possible with an indicator as selective as the reed indicator to have the beacon serve several courses simultaneously by using modulation frequencies separated 20 cycles for each course.

The shock-proof mounting is made by suspending an aluminum box on springs at its eight corners. The indicator plugs into the front end of the box which is open. A catch is provided for holding it in. A stop on the rear prevents the springs from being stretched unduly when the indicator is plugged in or pulled out. This stop has plenty of clearance in order to give free movement to the case holding the indicator.

The reeds of this indicator may be calibrated for equality of deflection either by shunting one driving magnet coil with a resistance or by bending an aluminum damper on the reeds so as to give greater or less damping.

\section{REAR-DRIVE, NONPOLARIZED INDICATOR, TYPE E}

This indicator (shown in fig. 13) was designed to overcome some of the disadvantages of the previous types. It is the same size as the type D indicator, so that it will plug into the same shock-proof mounting. It is somewhat heavier, however. Four driving coils similar to those used in the type A indicator are used in this indicator. It is radically different in design, being somewhat similar to the commercial type frequency indicator which has a number of reeds mounted in a common armature which is actuated by an electromagnet. This design was modified somewhat, since it was found that with the two reeds on a common armature there was a noticeable reaction between them, since the armature was light in weight and the ends of the reeds were not weighted. By putting each reed on a separate armature, each armature being actuated by a separate electromagnet, this trouble was overcome. The two actuating electromagnets were taken from ordinary telephone receivers. These each operate a soft-iron armature to which a reed is attached. The reeds 
are only $1.5 \mathrm{~mm}$ wide in this indicator. They may be of any desired material, since it is not necessary that it be magnetic. The alloy elinvar was therefore used for the reeds, since the modulus of elasticity of this material is practically independent of the temperature. This is a rather important factor, as will be noted from the data shown. (Fig. 14.) From these data it will be noted that a change in $60^{\circ} \mathrm{C}$.

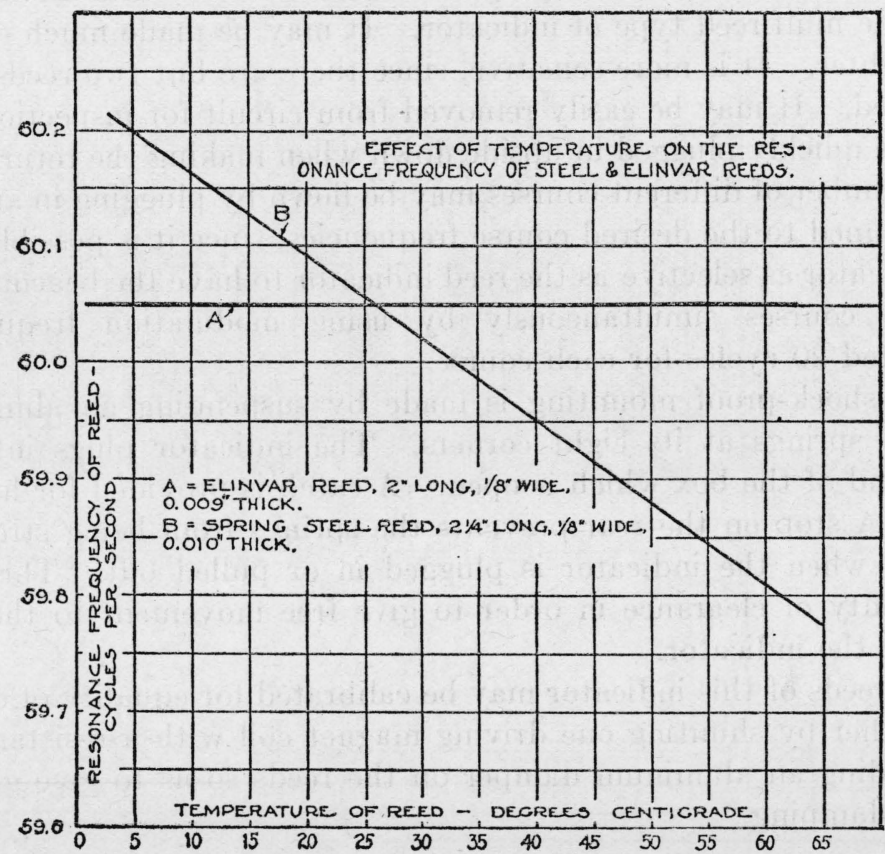

Fig. 14.-Effect of temperature on the resonance frequency of steel and elinvar reeds

of a steel reed in this indicator caused its resonance frequency to change from 60.20 to 59.78 cycles, whereas with a similar change in temperature of an elinvar reed no change in the resonance frequency could be noted. For the steel reed, therefore, the change in frequency with temperature is 0.0117 per cent per degree centigrade. This figure agrees well with the commonly accepted value. Since temperature changes of the order of $60^{\circ} \mathrm{C}$. are to be expected on aircraft, it is evident that the use of this material for the reeds in this indicator is an improvement, since it is not necessary to dampen the reed so much in order to hold it in tune with changing temperature. Some damping of the elinvar reed, however, is desirable, in order to hold it in tune in case the modulating frequencies of the tuning forks at the transmitting beacon should drift slightly.

Another advantage of the type $\mathrm{E}$ indicator is that the resonance frequency of the reeds in this indicator is not altered by their ampli- 
tude. It was found that with other types of indicators when the driving force was applied to the free end of the reed the natural period of the reed was a function of the amplitude. This is shown in Figure 15 , in which curve No. 1 shows no variation in the resonance frequency of the reed in the type $\mathrm{E}$ indicator when the driving force is applied to the fixed end of the reed even up to a deflection of $12 \mathrm{~mm}$.

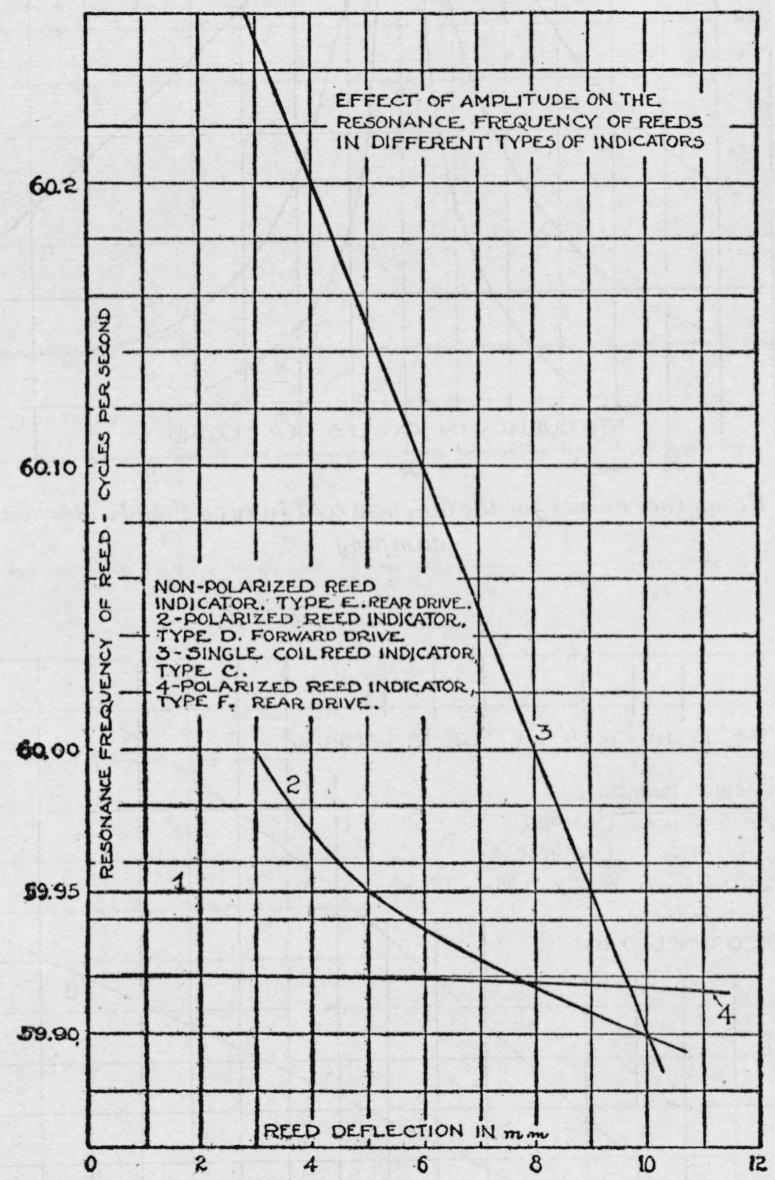

FIG. 15.-Effect of amplitude of vibration of reeds in different types of indicators

However, in curve 2, which is for the type D indicator, a change of one-tenth of a cycle was noted for a change in amplitude of the reed from 3 to $10 \mathrm{~mm}$. The period of the reed drops with increasing amplitude. Curve No. 3 for the type C indicator shows an even worse variation. Figure 16 shows the resonance curves for a 60 -cycle reed in the type $\mathrm{E}$ indicator, with and without damping on the reed. Different voltages were used on the reed coils for each resonance curve. 


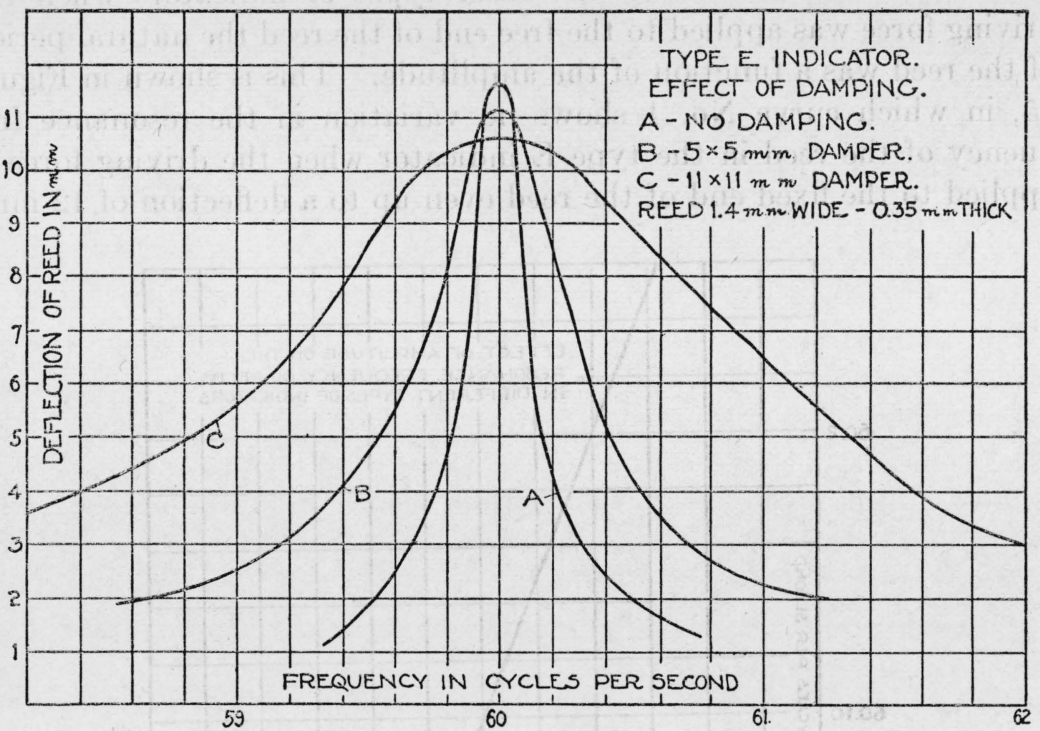

FIG. 16.-Resonance curves for the 60-cycle reed in type $E$ indicator with different damping

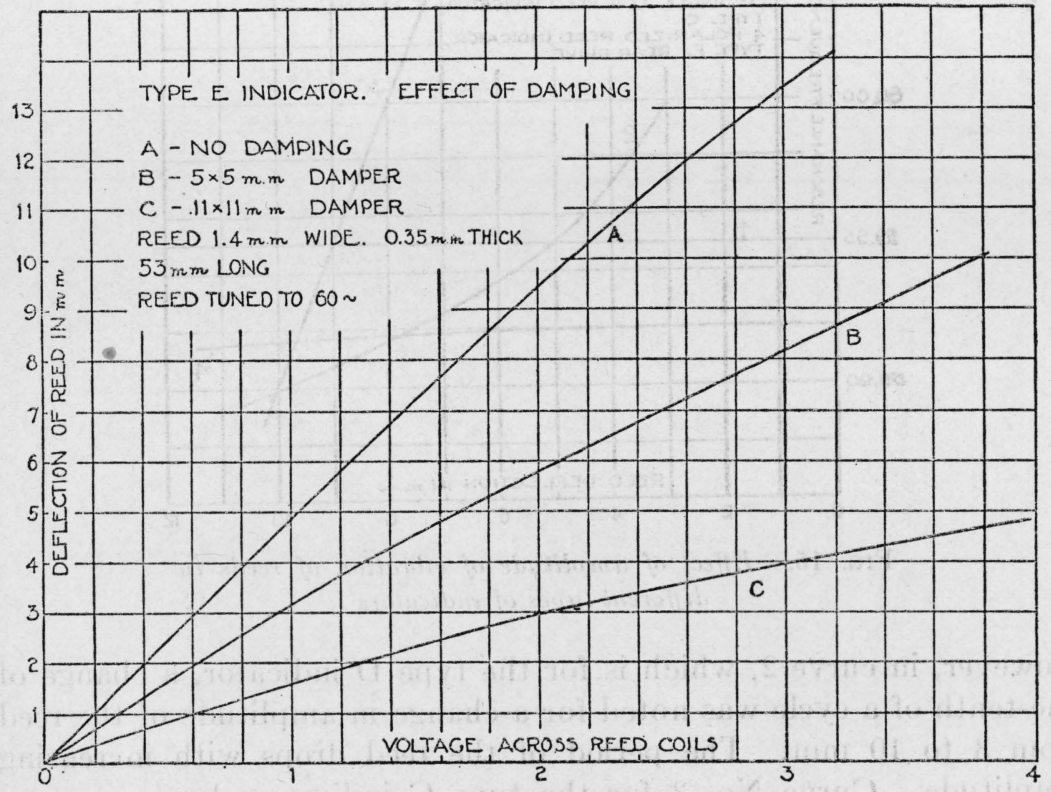

FIg. 17.-Voltage required to operate 60-cycle reed in type $E$ indicator with different damping 
Figure 17 shows the voltage required to operate the reeds with and without damping.

A disadvantage of this indicator is that, due to the untuned armature, it is not as free from the effects of bad interference as is the other types of indicators.

It is important with the type $\mathrm{E}$ indicator to have sufficient spring tension on the spring holding the soft-iron armature and sufficient clearance between the armature and pole pieces so that with a strong interfering signal the armature, which is not tuned, will not chatter against the pole pieces. This trouble can not occur in the other types of indicator, since the only moving element is the reed, which, being tuned, will not respond to the interfering signal. This spring stiffness and large clearance between armature and pole pieces in the type $\mathrm{E}$ indicator reduces its sensitivity to nearly that of the type $\mathrm{D}$ indicator, but it is requisite in order to obtain satisfactory operation of the reeds under practical operating conditions on the airplane.

\section{REAR-DRIVE, POLARIZED REED, TYPE F}

It had been noticed in the early experiments with the type A indicator that a permanent magnet, when correctly located near the reed, tended to polarize it, giving it a greater amplitude of vibration.

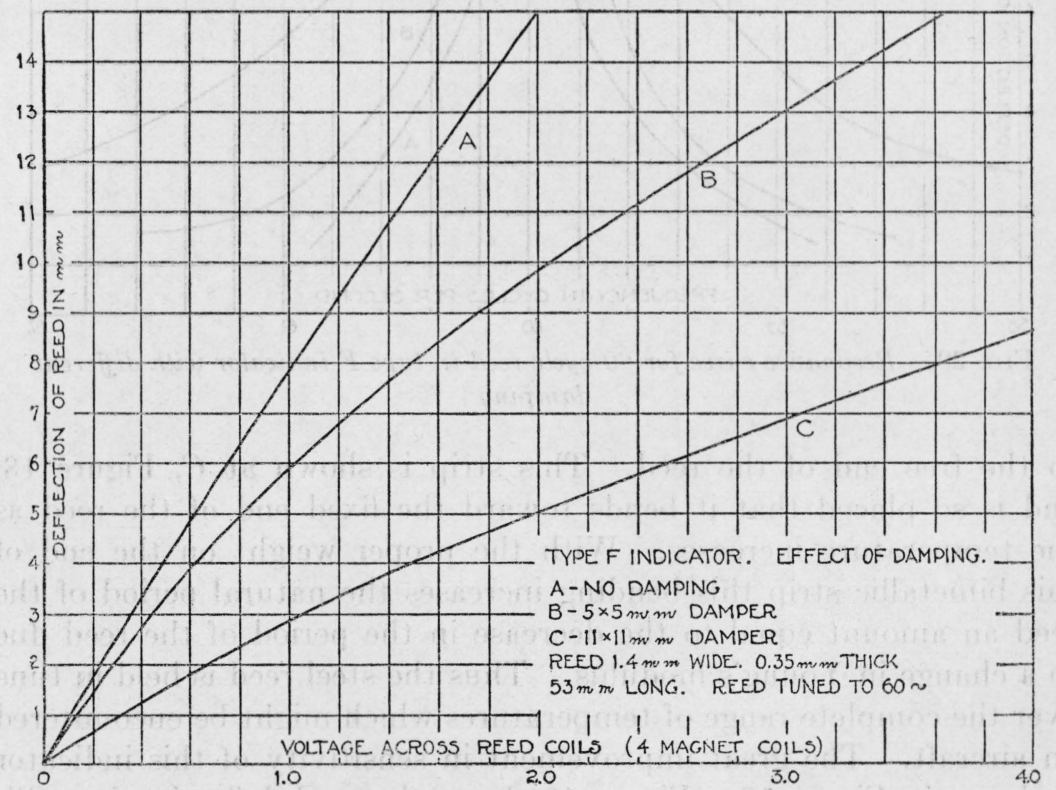

Fig. 19.-Voltage required to operate 60-cycle reed in type $F$ indicator with different damping

This feature was made use of in the type $\mathrm{F}$ indicator, as shown in Figure 18, in which two permanent magnets, $A$ and $B$, strongly 
polarize the portion of the reeds directly under the driving electromagnets. These four electromagnets are similar to those used in the types $\mathrm{A}, \mathrm{D}$, and $\mathrm{E}$ indicators. This greatly increased the sensitivity. In addition to this, since the driving force is applied near the fixed end of the reed, the resonance frequency is practically independent of the amplitude, as shown in curve No. 4. (Fig. 15.) Due to the nature of the drive, being push-pull as in the type A indicator, the selectivity of the type $\mathrm{A}$ indicator is preserved in the type $\mathrm{F}$ indicator.

Since in this indicator it was necessary to use a magnetic material for the reed in order to polarize it, the metal elinvar could not be used as it is only slightly magnetic. It was found possible to use steel, however, since a method was devised for automatically correcting for the change in natural period of a steel reed due to change in temperature by the use of a small strip of bimetallic material soldered

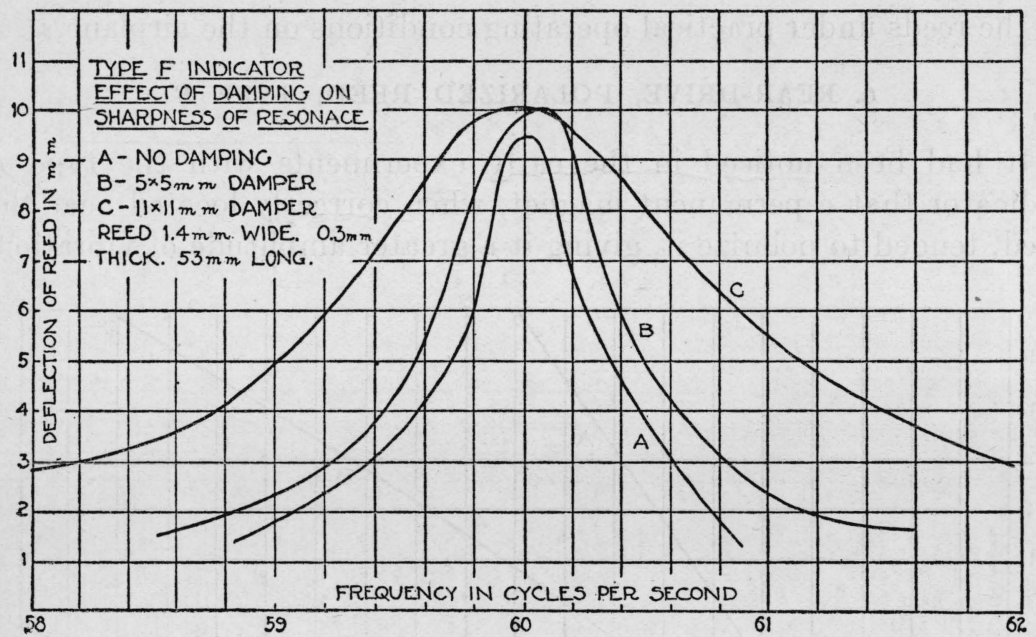

Fig. 20.-Resonance curve for 60-cycle reed in type $F$ indicator with different damping

to the free end of the reed. This strip is shown at $C$, Figure 18, and is so placed that it bends toward the fixed end of the reed as the temperature increases. With the proper weight on the end of this bimetallic strip this bending increases the natural period of the reed an amount equal to the decrease in the period of the reed due to a change in Young's modulus. Thus the steel reed is held in tune over the complete range of temperatures which might be encountered on aircraft. The great improvement in sensitivity of this indicator is shown in Figure 19. Figure 19 shows the reed deflection in millimeters plotted against the voltage across the reed driving coils for different sized dampers on the end of the reed. Figure 20 shows the resonance curves for the 60 -cycle reed in this indicator under the 


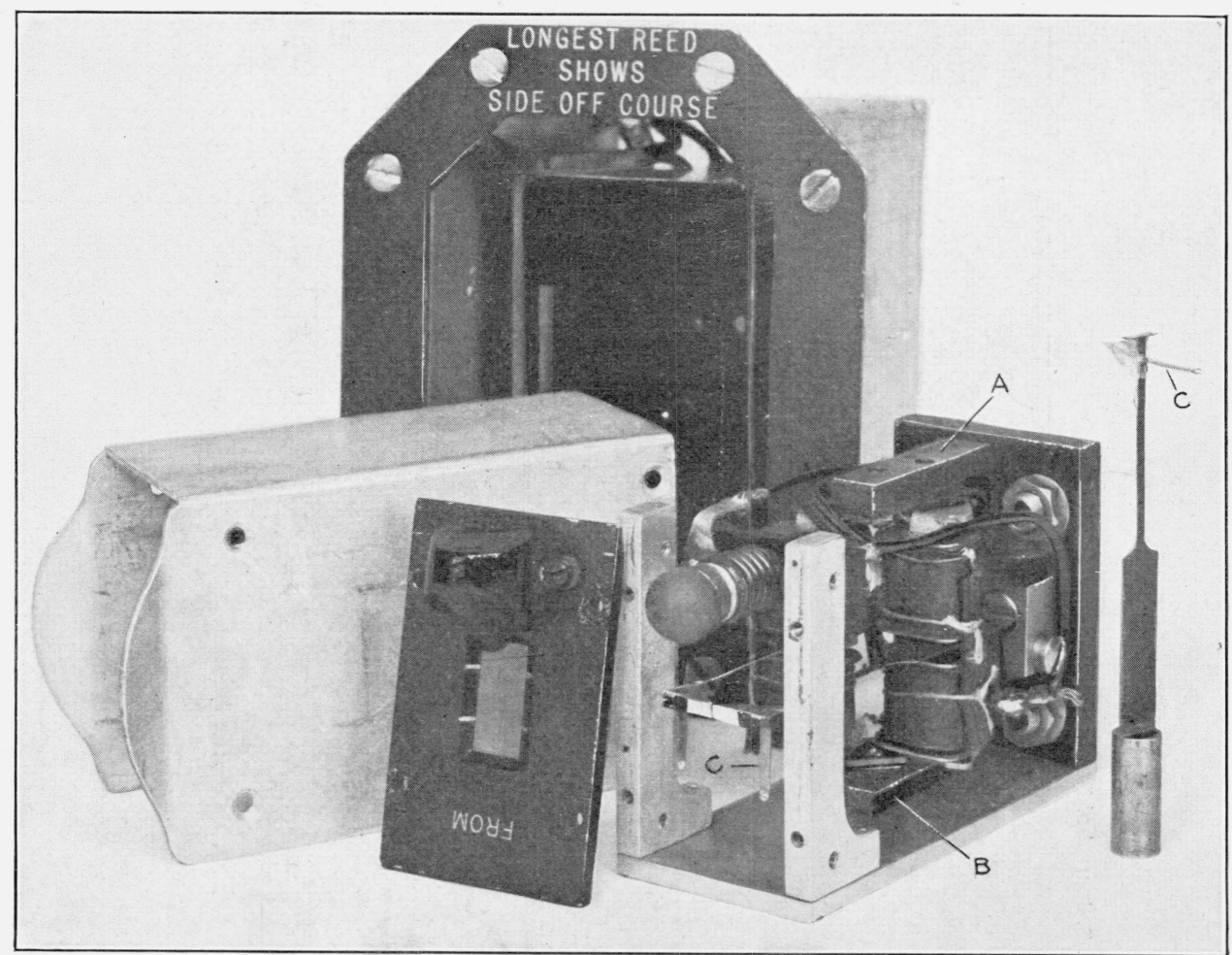

FIG. 18.-The type F indicator, polarized rear-drive reeds, compensated for effect of temperature 
B. S. Journal of Research, RP28

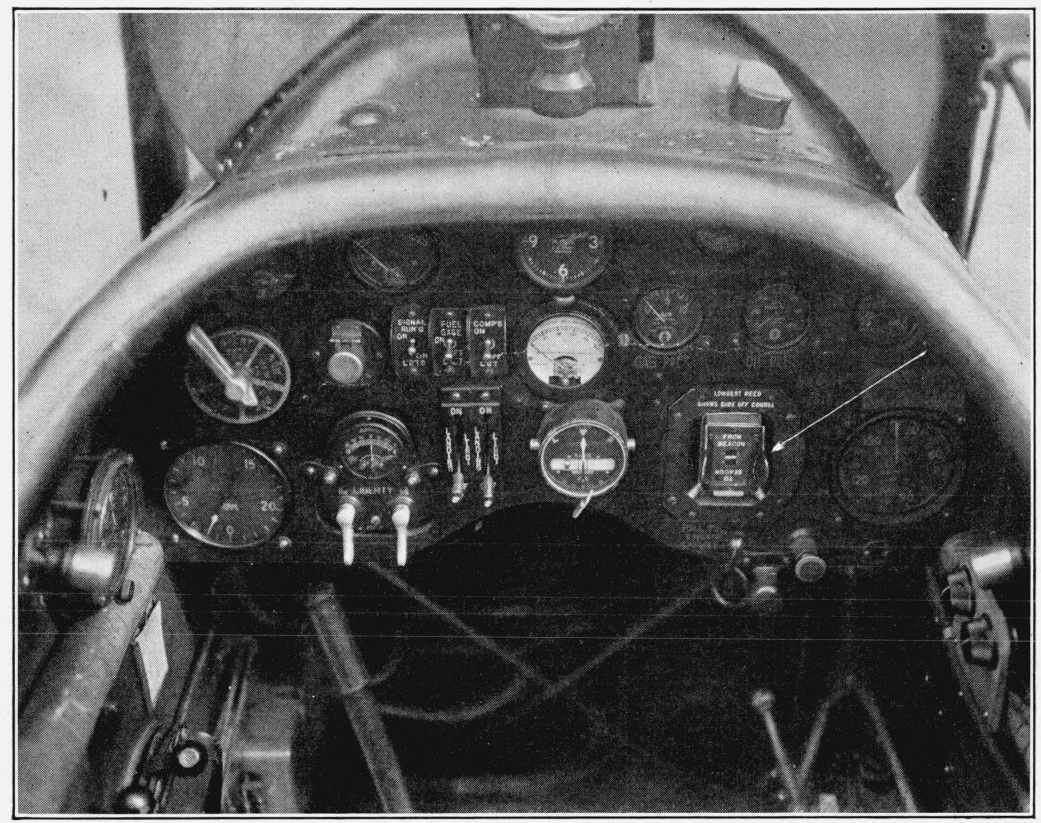

FIG. 21.--Reed indicator mounted on airplane instrument board 
same conditions of damping. Different voltages were applied to the reed coils for each curve. From Figure 19 it will be seen that even with the greatest damping, which feature, as stated before, is desirable, it is possible to obtain a proper working deflection of $8 \mathrm{~mm}$ with only 3.6 volts applied to the reed indicator driving coils and only 1 milliampere in these coils. This is an improvement over the operation of the type $\mathrm{E}$ indicator which, as shown in Figure 17, required approximately 7 volts to give the same deflection under the same conditions of damping. Externally the type $\mathrm{F}$ indicator looks like the type D indicator shown in Figures 11, 12, and 21. It plugs into the same shock-proof mounting.

\section{CONCLUSION}

The results obtained, in general, with the reed indicators in actual airplane flights are given in the paper ${ }^{2}$ referred to at the beginning of this paper. Figure 21 shows the visual indicator installed on the instrument board of a De Haviland plane. It is connected in place of the headphones on a 6-tube receiving set installed in the tail of the plane. From the flights made on the radiobeacon course under various conditions, designs of reed indicator and shock-proof mounting were worked out. These flights showed that when ignition interference made aural reception almost impossible the reeds functioned satisfactorily, owing to their insensitivity to any frequency other than that to which they are tuned. For the same reason, other stations, such as the marine beacons, did not interfere with the operation of the reeds, the audio modulation of their signal being 1,000 cycles, while with aural reception trouble was often experienced from this source. One of the most valuable features of the reed indicator is the fact that it gives a continuous indication to the pilot of his position with respect to the course. This indication is obtained without any other effort than a glance of the eye. This feature is particularly valuable, since in time of fog, when the device is most needed, the pilot is very much occupied and can only glance at a course-indicating device occasionally.

The author is indebted to $\mathrm{H}$. Pratt for helpful suggestions in connection with the design of the magnetic circuits in some of the indicators. Acknowledgment is due R. R. Gessford and D. O. Lybrand for constructing the indicator models and for suggestions pertaining to their mechanical design.

Washington, September 15, 1928.

${ }^{2}$ See footnote 1, p. 752. 
